Bangladesh J. Plant Taxon. 26(2): 299-313, 2019 (December)

(C) 2019 Bangladesh Association of Plant Taxonomists

\title{
MINOR EDIBLE FRUITS OF BANGLADESH
}

\author{
Mostafa Kamal Pasha and Shaikh Bokhtear Uddin* \\ Department of Botany, University of Chittagong, Chittagong 4331, Bangladesh
}

Keywords: Minor edible fruits, Bangladesh

\begin{abstract}
Minor edible fruits are the genetic resource of a country, playing a vital role as food, nutrition and medicine. Bangladesh having both tropical and sub-tropical climatic condition possesses a large number of species that produce minor edible fruits. The present study represents 255 species of minor edible fruit yielding plants of Bangladesh. Of them, 242 species belong to 58 families of Magnoliopsida and 13 species to three families of Liliopsida. The large minor fruit yielding families are Euphorbiaceae (20 spp.), Myrtaceae (18 spp.), Moraceae (15 spp.), Arecaceae (11 spp.), Sapindaceae (11 spp.), Anacardiaceae (10 spp.), Annonacae (10 spp.), Rutaceae (8 spp.), Verbenaceae (8 spp.) and Vitaceae ( $8 \mathrm{spp}$.). Three species are aquatic in nature and about 50 species are herbs, including 31 species of climbers or lianas, and 49 are shrubs and the remaining 156 species are trees. About 48 species are cultivated for fruits and the 35 species are both cultivated and wild. The remaining species are exclusively wild. A total of 53 exotic species are included in the cultivation. In most of the species, pericarp with mesocarp or the whole part of fruit is edible. In few cases either seed or kernel is edible, or in others the non-carpel part of flower. Summer is found as the most and winter as the least suitable fruit yielding seasons in a year.
\end{abstract}

\section{Introduction}

Fruits are eaten raw and their nutritive value lies in the presence of good amount of organic acids, carotenoids, vitamins and minerals. Fruits are an integral part of food needed to meet the mineral requirements of human body and to strengthen body defense mechanisms against various biotic and abiotic stresses and for proper health per capita requirement of fruits is $115 \mathrm{~g}$. On an average, fruits have been contributing to about 4\% to human nutrition (APCAEM, 2007). Utmost rural houses possess a home garden with fruit and timber plants that act as a source of income for many families and became the safety net during in hardship and natural disaster. The planting intensity has increased at least four folds in $65 \%$ of households during the last few years (Rahman and Rahman, 2014). Botanically fruit is the matured or ripe ovary. Sometimes thalamus, calyx and epicalyx, inflorescence or seeds are also developed as the major part of a fruit. Out of about 2,50,000 species in Magnoliophyta, about 30,000 species have been identified as edible fruit yielding, of which about 7,000 species have found cultivated in the World (Wilson, 1992). Minor fruits are those that are consumable to the human beings but are relatively less palatable than other mainstream fruits, which have lesser demand in the market and are grown to a limited extent only (Srivastava et al., 2017). Many of the minor or under-utilized fruits are important in social, economic, biodiversity and conservation aspects on a regional and local basis. They also provide the source of nutrition of wild animals and birds.

Many floristic works in this region mentioned about the edible fruits of Bangladesh (Humphrey et al., 1921; Heinig, 1925; Siddiqui et al., 2007 and Ahmed et al., 2008-2009) and its surrounding areas (Grierson and Long, 1983-1991; Guha-Bakshi, 1984; Naskar, 1993, and Noltie, 1994).

*Corresponding author. Email: bokhtear@cu.ac.bd 
The first comprehensive record about the edible fruits of Bangladesh was published by Khan (1974), who reported 43 species of fruits that are cultivated. Das (1982) recorded 60 species of fruits which are growing only in wild state. Later on, Rashid et al. (1987) recorded 40 cultivated fruits of Bangladesh. Subsequently Begum (2004) reported 55 species, which are only in cultivation. Finally, Roy (2007) made an extensive record of fruits, which are both cultivated and wild, numbering a total of 120 species. Rahim et al. (2011) reported 67 minor fruit yielding plants of Bangladesh that are growing in the Germplasm Centre at Bangladesh Agriculture University. The minor fruits contributed about $8.38 \%$ production of the total fruit yield of Bangladesh (BBS, 2011).

There are 250 edible fruits in the Philippines (Hill, 1951). In Malaysia, there are about 500 species of fruit plants of which 100 species are cultivated (Zakri and Mohammad, 1997). On the other hand, Joshi (1998) reported 162 species and Suresh et al. (2014) reported only 21 species of minor fruit yielding plants from India.

New scope and possibility about utilization of wild fruits is increasing. At least 30 species are already known in Bangladesh for their therapeutic values apart from their nutrition values (Rahman and Rahman, 2014). Some are antidiabetic and antioxidant. Quite a few of these have excellent flavors and attractive colour. Many natural food colours, mostly anthocyanins, are now demanding. Furthermore, many minor fruits may be valuable for food processing like jam, jelly, sauce, pickles, juice and food additives.

A preliminary botanical survey has been done by us and the study indicated that many more species are yet to be recorded or compiled for full listing of the minor fruit yielding plant resource of Bangladesh. Therefore, this study aims at providing and updating available taxonomic information of the minor edible fruit yielding plants of Bangladesh.

\section{Materials and Methods}

An extensive field survey has been conducted in different localities of 14 districts of Bangladesh namely, Chittagong, Rangamati, Bandarban, Khagrachari, Kumilla, Brahmanbaria, Mymensingh, Khulna, Jeshore, Satkhira, Sylhet, Moulavibazar, Rajshahi and Bogura districts (Fig. 1) from 2006 to 2018 following group discussion, household survey and market survey techniques. In addition, primary information on minor and wild fruit was collected from different secondary resources (scientific papers, books, internet etc.). The collected samples were identified by consulting the available relevant literatures. Furthermore, the specimens located at the herbaria CUH, BFRIH and DACB were also studied. In order to accommodate vast array of information, a small representative list of wild and minor fruits has been prepared with their up-to-date nomenclature (Pasha and Uddin 2013 and www.theplantlist.org). Information on the availability, habit condition and status of the plants was also collected.

\section{Results and Discussion}

A total of 255 minor edible fruit yielding species belonging to 149 genera under 61 families have been presented alphabetically (Table 1). 15 of these species under three families belong to the Liliopsida and the remaining species under 58 families belong to Mangnoliopsida. The Euphorbiaceae is recorded as the largest minor fruit yielding family (20 spp.), which is followed by Myrtaceae (18 spp.), Moraceae (15 spp.), Arecaceae (11 spp.), Sapindaceae (11 spp.), Anacardiaceae (11 spp.), Annonacae (10 spp.), Rutaceae (8 spp.), Verbenaceae (8 spp.) and Vitaceae ( 8 spp.) families. These ten large families constitute about $47 \%$ of the total species found as minor fruit yielding (Fig. 2). 


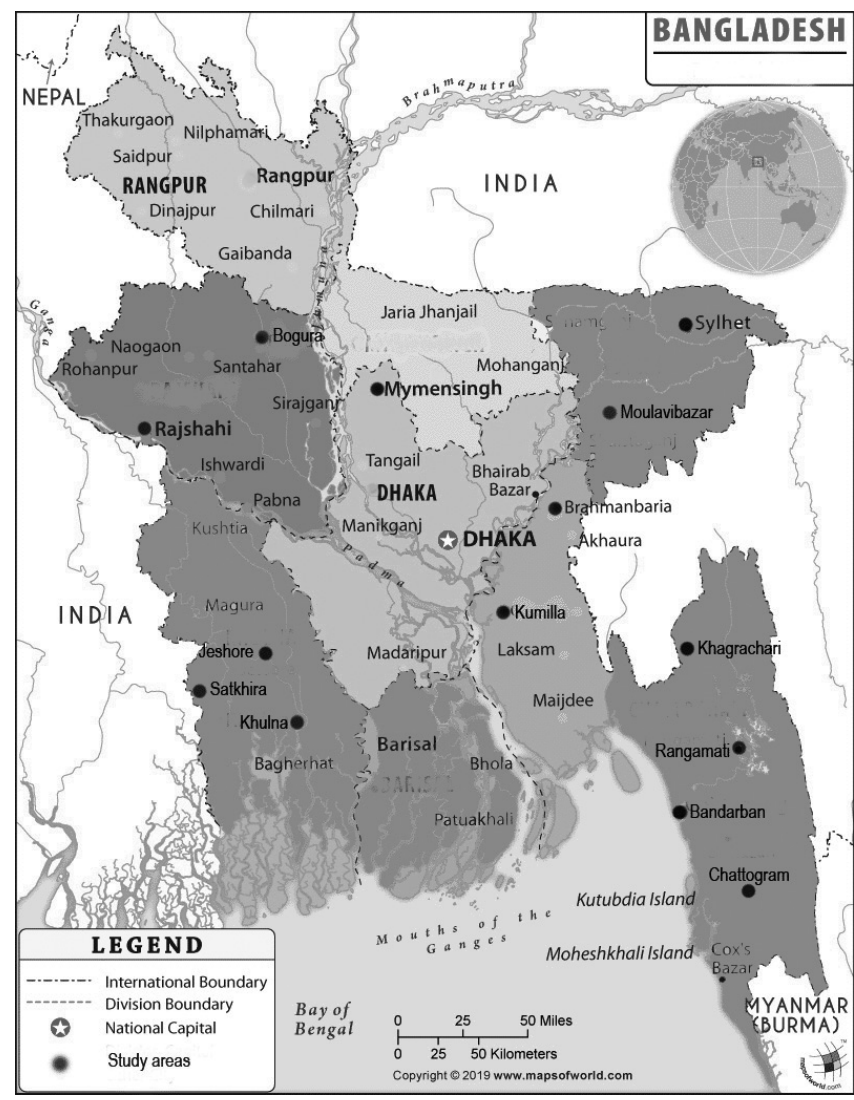

Fig. 1. Map of Bangladesh showing the study areas (Source: www.mapsofworld.com).

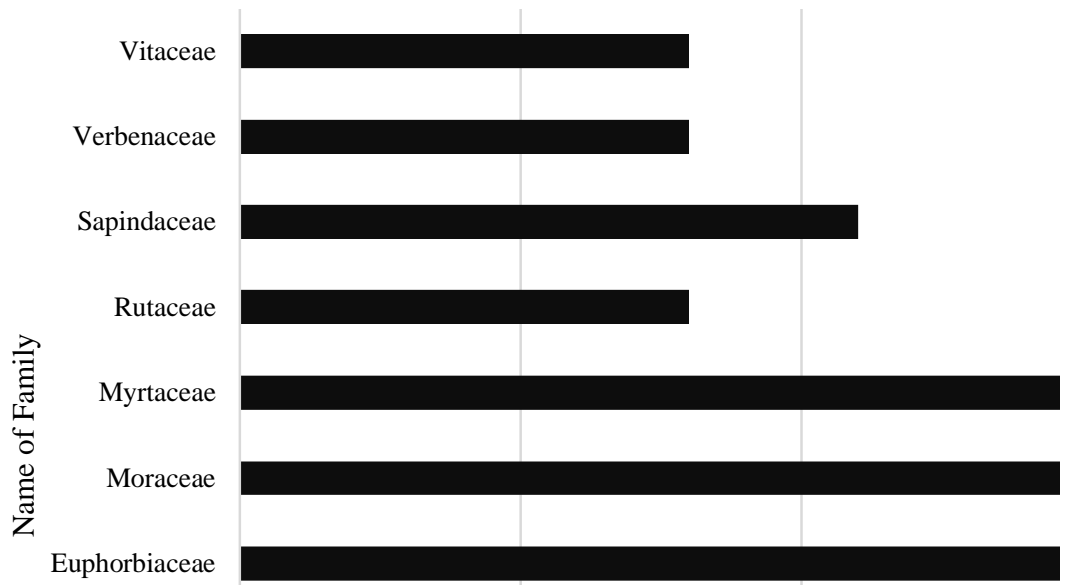

Fig. 2. The ten large minor fruit yielding families of Bangladesh. 
Table 1. The list of minor fruit yielding plant species of Bangladesh.

\begin{tabular}{|c|c|c|c|c|c|c|}
\hline $\begin{array}{l}\text { Sl. } \\
\text { No. }\end{array}$ & Botanical Name & Family name & Local Names & Habit & $\begin{array}{c}\text { Cultivated } \\
\text { (C)/ } \\
\text { Wild (W) }\end{array}$ & $\begin{array}{c}\text { Indigenous } \\
\text { (In)/ } \\
\text { Exotic (E) }\end{array}$ \\
\hline 1. & $\begin{array}{l}\text { Acronychia pedunculata (L.) } \\
\text { Miq. }\end{array}$ & Rutaceae & Bon jamir & Small tree & $\mathrm{W}$ & In \\
\hline 2. & Aglaia perviridis Hiern & Meliaceae & Sabuj amoor & Medium tree & $\mathrm{W}$ & In \\
\hline 3. & $\begin{array}{l}\text { Alangium salviifolium (L.f.) } \\
\text { Wangerin }\end{array}$ & Alangiaceae & Ankora, Akarkanta & Medium tree & $\mathrm{W}$ & In \\
\hline 4. & $\begin{array}{l}\text { Aleurites moluccanus (L.) } \\
\text { Willd. }\end{array}$ & Euphorbiaceae & Akhrot & Medium tree & $\mathrm{W}$ & Ex. \\
\hline 5. & $\begin{array}{l}\text { Allophylus cobbe (L.) } \\
\text { Raeuschel var. villosa (Roxb.) } \\
\text { Prain }\end{array}$ & Sapindaceae & $\begin{array}{l}\text { Chita, Rakhal } \\
\text { chita, Aita chita }\end{array}$ & $\begin{array}{l}\text { Shrub or small } \\
\text { tree }\end{array}$ & W & In \\
\hline 6. & $\begin{array}{l}\text { Alphonsea lutea (Roxb.) } \\
\text { Hook.f. \& Thomson }\end{array}$ & Annonaceae & Fonseti & Small tree & W & In \\
\hline 7. & $\begin{array}{l}\text { A. ventricosa (Roxb.) Hook.f. } \\
\& \text { Thomson }\end{array}$ & Annonaceae & Fonsetricosa & Small tree & $\mathrm{W}$ & In \\
\hline 8. & $\begin{array}{l}\text { Ampelocissus barbata (Wall.) } \\
\text { Planch. }\end{array}$ & Vitaceae & Jarila lahari & $\begin{array}{l}\text { Herbaceous } \\
\text { climber }\end{array}$ & $\mathrm{W}$ & In \\
\hline 9. & A. latifolia (Roxb.) Planch. & Vitaceae & $\begin{array}{l}\text { Gowalia lata, } \\
\text { Govila, Peribel }\end{array}$ & $\begin{array}{l}\text { Herbaceous } \\
\text { climber }\end{array}$ & $\mathrm{W}$ & In \\
\hline 10. & $\begin{array}{l}\text { Ampelygonum chinense (L.) } \\
\text { Lindley }\end{array}$ & Polygonaceae & $\begin{array}{l}\text { Mohicharan sak, } \\
\text { Kaker bantabhat }\end{array}$ & $\begin{array}{l}\text { Herbaceous } \\
\text { climber }\end{array}$ & $\mathrm{W}$ & In \\
\hline 11. & Anacardium occidentale $\mathrm{L}$. & Anacardiaceae & Kaju badam & Small tree & $\mathrm{C}$ & Ex \\
\hline 12. & Annona muricata $\mathrm{L}$. & Annonaceae & Muri at & Small tree & $\mathrm{C}$ & Ex \\
\hline 13. & A. reticulata $\mathrm{L}$. & Annonaceae & Nona ata & Small tree & $\mathrm{C}$ & Ex \\
\hline 14. & A. squamosa $\mathrm{L}$. & Annonaceae & Sharifa & Small tree & $\mathrm{C}$ & Ex \\
\hline 15. & Anthocephalus cadamba Miq & Rubiaceae & Kadam & Large tree & $\mathrm{C} \& \mathrm{~W}$ & In \\
\hline 16. & Antidesma acidum Retz. & Euphorbiaceae & Amrul, Chutki & Small tree & $\mathrm{W}$ & In \\
\hline 17. & A. acuminatum Wall. & Euphorbiaceae & Shial buka & Small tree & $\mathrm{W}$ & In. \\
\hline 18. & A. bunius (L.) Spreng. & Euphorbiaceae & Banshial buka & Small tree & W & In \\
\hline 19. & A. khasianum Hook.f. & Euphorbiaceae & Khasia jam & Small tree & $\mathrm{W}$ & In \\
\hline 20. & $\begin{array}{l}\text { A. montanum Blume var. } \\
\text { montanum }\end{array}$ & Euphorbiaceae & Shial buka & Small tree & $\mathrm{W}$ & In \\
\hline 21. & $\begin{array}{l}\text { Aporosa octandra( Buch.- } \\
\text { Ham ex D.Don) Vickery }\end{array}$ & Euphorbiaceae & Pat kharolla & Small tree & $\mathrm{W}$ & In \\
\hline 22. & A. aurea Hook.f. & Euphorbiaceae & Kechuan & Small tree & $\mathrm{W}$ & In \\
\hline 23. & $\begin{array}{l}\text { Artocarpus chama Buch.Ham. } \\
\text { ex Wall. }\end{array}$ & Moraceae & $\begin{array}{l}\text { Chaplash, } \\
\text { Chambal }\end{array}$ & Large tree & W & In \\
\hline 24. & A. lacucha Buch.-Ham. & Moraceae & Deophal & Large tree & $\mathrm{W} \& \mathrm{C}$ & In \\
\hline 25. & Averrhoa bilimbi $\mathrm{L}$. & Oxalidaceae & Bilimbi & Small tree & $\mathrm{C}$ & Ex \\
\hline 26. & A. carambola $\mathrm{L}$. & Oxalidaceae & Kamranga & Small tree & $\mathrm{C}$ & Ex \\
\hline 27. & Avicennia alba Blume & Verbenaceae & $\begin{array}{l}\text { Sada baen, Maricha } \\
\text { baen }\end{array}$ & Large tree & $\mathrm{W}$ & In \\
\hline 28. & Baccaurea ramiflora Lour. & Euphorbiaceae & Latkan, Bhubi & Medium tree & $\mathrm{W} \& \mathrm{C}$ & In \\
\hline 29. & Bauhinia vahlii Wight \& Arn. & Caesalpiniaceae & Lata-kanchan & Climbing shrub & $\mathrm{W} \& \mathrm{C}$ & In \\
\hline 30. & $\begin{array}{l}\text { Bouea oppositifolia (Roxb.) } \\
\text { Meissner }\end{array}$ & Anacardiaceae & Bhallam, Uriaam & Medium tree & $\mathrm{W}$ & In \\
\hline 31. & Bridelia retusa (L.) A.Juss. & Euphorbiaceae & $\begin{array}{l}\text { Kata kushui, } \\
\text { Akdana }\end{array}$ & Small tree & $\mathrm{W}$ & In \\
\hline 32. & B. stipularis (L.) Blume & Euphorbiaceae & Pat khowi, Harinhara & Climbing shurb & W & In \\
\hline
\end{tabular}


Table 1 Contd.

\begin{tabular}{|c|c|c|c|c|c|c|}
\hline $\begin{array}{l}\text { Sl. } \\
\text { No. }\end{array}$ & Botanical Name & Family name & Local Names & Habit & $\begin{array}{c}\text { Cultivated } \\
\text { (C)/ } \\
\text { Wild (W) } \\
\end{array}$ & $\begin{array}{c}\text { Indigenous } \\
\text { (In)/ } \\
\text { Exotic (E) }\end{array}$ \\
\hline 33. & Buchanania lancifolia Roxb. & Anacardiaceae & Cheerojee oil plant & Small tree & $\mathrm{W}$ & In \\
\hline 34. & B. lanzan Spreng. & Anacardiaceae & Piyal & Small tree & $\mathrm{W}$ & In \\
\hline 35. & Caesalpinia digyna Rottler & Caesalpiniaceae & Kochoi, Teri pods & Shrubby climber & $\mathrm{W}$ & In \\
\hline 36. & Calamus latifolius Roxb. & Arecaceae & $\begin{array}{l}\text { Kerak bet, Budum } \\
\text { bet }\end{array}$ & $\begin{array}{l}\text { Extensive } \\
\text { climber }\end{array}$ & $\mathrm{W} \& \mathrm{C}$ & In \\
\hline 37. & C. longisetus Griff. & Arecaceae & Uddum bet & Robust shrub & $\mathrm{W} \& \mathrm{C}$ & In \\
\hline 38. & C. tenuis Roxb. & Arecaceae & Jali bet, Sanchi bet & Climbing shrub & $\mathrm{W} \& \mathrm{C}$ & In \\
\hline 39. & C. viminalis Willd. & Arecaceae & $\begin{array}{l}\text { Bara bet, Khor } \\
\text { khoijja bet }\end{array}$ & Climbing shrub & $\mathrm{W} \& \mathrm{C}$ & In \\
\hline 40. & Callicarpa arborea Roxb. & Verbenaceae & $\begin{array}{l}\text { Bormala, Khoja, } \\
\text { Makanchi }\end{array}$ & Small tree & $\mathrm{W}$ & In \\
\hline 41. & $\begin{array}{l}\text { Calophyllum polyanthum Wall } \\
\text { ex Choisy }\end{array}$ & I.Clusiaceae & Kamdob & Medium tree & $\mathrm{W}$ & In \\
\hline 42. & Canarium bengalense Roxb. & Burseraceae & Dhuna rata & Buttressed tree & $\mathrm{W}$ & In \\
\hline 43. & Capparis zeylanica $\mathrm{L}$. & Capparaceae & Kalookra & Large shrub & $\mathrm{W}$ & In \\
\hline 44. & Carallia brachiata Roxb. & Rhizophoraceae & $\begin{array}{l}\text { Roskao, Lotkao, } \\
\text { Matan }\end{array}$ & Small tree & W & In \\
\hline 45. & Careya arborea Roxb. & Lecythidaceae & Kumba bidipata, & Medium tree & $\mathrm{W}$ & In \\
\hline 46. & Carissa carandas $\mathrm{L}$. & Apocynaceae & Karamcha & $\begin{array}{l}\text { Bushy shrub or } \\
\text { small tree }\end{array}$ & $\mathrm{C}$ & Ex \\
\hline 47. & C. spinarum $\mathrm{L}$. & Apocynaceae & Misti karamcha & Shrub & W & In \\
\hline 48. & Cassytha filiformis $\mathrm{L}$. & Lauraceae & Akasbel & Annual herb & $\mathrm{W}$ & In \\
\hline 49. & $\begin{array}{l}\text { Castanopsis indica (Roxb. ex } \\
\text { Lindl.) A.DC. }\end{array}$ & Fagaceae & $\begin{array}{l}\text { Batna, Shil batna, } \\
\text { Khiri badam }\end{array}$ & Medium tree & $\mathrm{W}$ & In \\
\hline 50. & $\begin{array}{l}\text { C. purpurella (Miq.) N.P. } \\
\text { Balakr. }\end{array}$ & Fagaceae & $\begin{array}{l}\text { Kata shingu, } \\
\text { Batna }\end{array}$ & Medium tree & W & In \\
\hline 51. & C. tribuloides (Sm.) A.DC. & Fagaceae & $\begin{array}{l}\text { Sili batna, Bara } \\
\text { hinguri }\end{array}$ & Medium tree & W & In \\
\hline 52. & Chrysophyllum cainito L. & Sapotaceae & Taroka phol & Medium tree & $\mathrm{C}$ & Ex \\
\hline 53. & $\begin{array}{l}\text { Chylocalyx perfoliatus (L.) } \\
\text { Hassk. ex. Miq. }\end{array}$ & Polygonaceae & Kanta tokpata & Annual herb & $\mathrm{C} \& \mathrm{~W}$ & In \\
\hline 54. & $\begin{array}{l}\text { Citrus assamensis S.Datta } \\
\& \text { S.C.Bhattacharya }\end{array}$ & Rutaceae & Ada jamir & Large shrub & $\mathrm{C}$ & In \\
\hline 55. & C. aurantium $\mathrm{L}$. & Rutaceae & $\begin{array}{l}\text { Satkora, Kaffir } \\
\text { lime }\end{array}$ & Medium tree & $\mathrm{C}$ & In \\
\hline 56. & Cordia dicotoma G.Forst. & Boraginaceae & Bohal, Kalahuza & Medium Tree & W & In \\
\hline 57. & $\begin{array}{l}\text { Daemonorops jenkinsiana } \\
\text { (Griff.) Mart. }\end{array}$ & Arecaceae & $\begin{array}{l}\text { Golla bet, Maj } \\
\text { jenkins }\end{array}$ & Climbing shrub & $\mathrm{W} \& \mathrm{C}$ & In \\
\hline 58. & Dillenia indica $\mathrm{L}$. & Dilleniacae & Chalta & Medium tree & $\mathrm{W} \& \mathrm{C}$ & In \\
\hline 59. & D. pentagyna Roxb. & Dilleniacae & Banchalta & Medium tree & $\mathrm{W}$ & In. \\
\hline 60. & Dimocarpus longan Lour. & Sapindaceae & $\begin{array}{l}\text { Ashphal, } \\
\text { Kathlichu, }\end{array}$ & Medium tree & $\mathrm{C} \& \mathrm{~W}$ & In \\
\hline 61. & Diospyros blancoi A.DC. & Ebenaceae & Beelati gab & Medium tree & $\mathrm{C}$ & Ex \\
\hline 62. & D. malabarica (Desr.) Kostel. & Ebenaceae & Deshi gab & Medium tree & $\mathrm{W} \& \mathrm{C}$ & In \\
\hline 63. & D. melanoxylon Roxb. & Ebenaceae & $\begin{array}{l}\text { Bidipata, } \\
\text { Tendupata }\end{array}$ & Medium tree & $\mathrm{W}$ & In \\
\hline
\end{tabular}


Table 1 Contd.

\begin{tabular}{|c|c|c|c|c|c|c|}
\hline $\begin{array}{l}\text { Sl. } \\
\text { No. }\end{array}$ & Botanical Name & Family name & Local Names & Habit & $\begin{array}{c}\text { Cultivated } \\
\text { (C)/ } \\
\text { Wild (W) }\end{array}$ & $\begin{array}{l}\text { Indigenous } \\
\text { (In)/ } \\
\text { Exotic (E) }\end{array}$ \\
\hline 64. & D. toposia Buch.-Ham. & Ebenaceae & $\begin{array}{l}\text { Katgula, Toposi, } \\
\text { Gab gulal }\end{array}$ & Medium tree & $\mathrm{W}$ & In \\
\hline 65. & Dodonaea viscosa (L.) Jacq. & Sapindaceae & Paniaphul & Small tree & $\mathrm{C}$ & Ex \\
\hline 66. & $\begin{array}{l}\text { Drypetes assamica (Hook.f.) } \\
\text { Pax \& K.Hoffm. }\end{array}$ & Euphorbiaceae & Ban bokul & Medium tree & $\mathrm{W}$ & In \\
\hline 67. & $\begin{array}{l}\text { D. subsessilis (Kurz) } \\
\text { Pax \& K. Hoffm. }\end{array}$ & Euphorbiaceae & Chato drypet & Small tree & W & In \\
\hline 68. & Duchesnea indica Andt. & Rosaceae & Jongli strawberry & Perennial herb & $\mathrm{W}$ & In \\
\hline 69. & Ehretia serrata Roxb. & Boraginaceae & Kala huja & Medium tree & W & In \\
\hline 70. & Elaeagnus latifolia $\mathrm{L}$. & Elaeagnaceae & Bonjara & Scandent shrub & $\mathrm{W}$ & In \\
\hline 71. & $\begin{array}{l}\text { Elaeocarpus angustifolius } \\
\text { Blume }\end{array}$ & Elaeocarpaceae & Rudraksha & Medium tree & W & In \\
\hline 72. & $\begin{array}{l}\text { E. tectorius (Lour.) } \\
\text { Poir. }\end{array}$ & Elaeocarpaceae & Tekopai olive & Medium tree & W & In \\
\hline 73. & Embelia ribes Burm.f. & Myrsinacreae & Biranga & Scandent shrub & W & In \\
\hline 74. & $\begin{array}{l}\text { Eriglossum rubiginosum } \\
\text { Blume }\end{array}$ & Sapindaceae & $\begin{array}{l}\text { Baraharina, Pitha, } \\
\text { Ritha }\end{array}$ & Medium tree & W & In \\
\hline 75. & $\begin{array}{l}\text { Eriobotrya japonica (Thunb.) } \\
\text { Lindl. }\end{array}$ & Rosaceae & Loquat & Small tree & $\mathrm{C}$ & Ex \\
\hline 76. & Eugenia roxburghii DC. & Myrtaceae & Hijli jam, Menadi & Small tree & W & In \\
\hline 77. & Euryale ferox Salisb. & Nymphaeaceae & Makhna, Makana, & Floating herb & $\mathrm{W}$ & In \\
\hline 78. & Ficus auriculata Lour. & Moraceae & Baradumur & Medium tree & $\mathrm{W}$ & In \\
\hline 79. & F. benjamina $\mathrm{L}$. & Moraceae & Pakur & Medium tree & $\mathrm{W}$ & In \\
\hline 80. & F. hispida $\mathrm{L}$. & Moraceae & Dumur, Khoksa & Small tree & $\mathrm{W}$ & In \\
\hline 81. & F. lanceolata Buch.-Ham. & Moraceae & $\begin{array}{l}\text { Buti dumur, } \\
\text { Erigachh }\end{array}$ & Medium tree & $\mathrm{W}$ & In \\
\hline 82. & F. oligodon Miq. & Moraceae & Oligo dumur & Medium tree & W & In \\
\hline 83. & F. pumila $\mathrm{L}$. & Moraceae & Lata dumur & $\begin{array}{l}\text { A climbing } \\
\text { Shrub }\end{array}$ & W & In \\
\hline 84. & F. racemosa $\mathrm{L}$. & Moraceae & Jagya dumur & Medium tree & W & In \\
\hline 85. & F. rumphii Blume & Moraceae & Gai aswathwa & $\begin{array}{l}\text { Medium sized } \\
\text { tree }\end{array}$ & $\mathrm{W}$ & In \\
\hline 86. & $\begin{array}{l}\text { Firmiana colorata (Roxb.) } \\
\text { R.Br. }\end{array}$ & Sterculiaceae & Ujal & Medium tree & $\mathrm{W}$ & In \\
\hline 87. & F. obovata Wall. & Sterculiaceae & Dima huri & Medium tree & $\mathrm{W}$ & In \\
\hline 88. & $\begin{array}{l}\text { Flacourtia indica (Burm.f.) } \\
\text { Merr. }\end{array}$ & Flacourtiaceae & Boicifol, Paniala & Large shrub & $\mathrm{W}$ & In \\
\hline 89. & F. inermis Roxb. & Flacourtiaceae & Loai & Small tree & W & In \\
\hline 90. & F. jangomas (Lour.) Raeusch. & Flacourtiaceae & $\begin{array}{l}\text { Painna gola, } \\
\text { Paniala }\end{array}$ & Small tree & $\mathrm{C} \& \mathrm{~W}$ & In \\
\hline 91. & Fragaria vesca $\mathrm{L}$. & Rosaceae & Strawberry & Annual herb & $\mathrm{C}$ & Ex \\
\hline 92. & F. indica Andr. & Rosaceae & Indian strawberry & Annual herb & W & In \\
\hline 93. & Garcinia cowa Roxb. ex DC. & Clusiaceae & Kau, Kao-gola & Medium tree & $\mathrm{W} \& \mathrm{C}$ & In \\
\hline 94. & G. lanceaefolia Roxb. & Clusiaceae & Thisuru & Large Shrub & W & In \\
\hline
\end{tabular}


Table 1 Contd.

\begin{tabular}{|c|c|c|c|c|c|c|}
\hline Sl. No & Botanical Name & Family name & Local Names & Habit & $\begin{array}{c}\text { Cultivated } \\
\text { (C)/ } \\
\text { Wild (W) }\end{array}$ & $\begin{array}{c}\text { Indigenous } \\
\text { (In)/ } \\
\text { Exotic (E) }\end{array}$ \\
\hline 95. & $\begin{array}{l}\text { G. pedunculata Roxb. ex. } \\
\text { Buch.-Ham. }\end{array}$ & Clusiaceae & $\begin{array}{l}\text { Tikul, Tikur, } \\
\text { Bor thekera }\end{array}$ & Medium tree & $\mathrm{W}$ & In \\
\hline 96. & $\begin{array}{l}\text { G. xanthochymus Hook. f. ex } \\
\text { T.Anderson }\end{array}$ & Clusiaceae & Tamal, Dem-gola & Medium tree & $\mathrm{W}$ & In \\
\hline 97. & $\begin{array}{l}\text { Garuga floribunda Decne. var } \\
\text { gambei (King ex W.W.Sm.) } \\
\text { Kilkman }\end{array}$ & Burseraceae & Jongli jiga, Garuga & Medium tree & $\mathrm{W}$ & In \\
\hline 98. & $\begin{array}{l}\text { Glochdion khasicum } \\
\text { (Muell.Arg.) Hook.f. }\end{array}$ & Euphorbiaceae & Khasia kachua & Small tree & W & In \\
\hline 99. & G. zeylanicum (Gaertn.) A.Juss. & Euphorbiaceae & Siloni kachua & $\begin{array}{l}\text { Shrub or small } \\
\text { tree }\end{array}$ & W & In \\
\hline 100. & $\begin{array}{l}\text { Glycosmis pentaphylla (Retz.) } \\
\text { A.DC. }\end{array}$ & Rutaceae & $\begin{array}{l}\text { Ash-sheora, } \\
\text { Datmajani }\end{array}$ & Bushy shrub & W & In \\
\hline 101. & Gmelina arborea Roxb. & Verbenaceae & Gamar & Medium tree & $\mathrm{W} \& \mathrm{C}$ & In \\
\hline 102. & G. asiatica $\mathrm{L}$. & Verbenaceae & Bhadhra & Medium tree & $\mathrm{C}$ & In \\
\hline 103. & Grewia abutilifolia Vent. & Tiliaceae & Kowri, Notk & Small tree & W & In \\
\hline 104 & G. asiatica $\mathrm{L}$. & Tiliaceae & $\begin{array}{l}\text { Phalsa, Sakri, } \\
\text { Pisla, Phalsa }\end{array}$ & Small tree & $\mathrm{C}$ & In \\
\hline 105. & G. hirsuta Vahl & Tiliaceae & Kukurbicha & Large shrub & W & In \\
\hline 106. & G. sapida Roxb. ex DC. & Tiliaceae & Chuhura & Herb & $\mathrm{W}$ & In \\
\hline 107. & $\begin{array}{l}\text { G. sclerophylla Roxb. ex } \\
\text { G.Don }\end{array}$ & Tiliaceae & Phalsa & Large Shrub & W & In \\
\hline 108. & G. tiliifolia Vahl & Tiliaceae & Dhomoni, Pholsa & Small tree & W & In \\
\hline 109. & $\begin{array}{l}\text { Haematocarpus thomsonii } \\
\text { Miers }\end{array}$ & Menispermaceae & Agniphol & Woody climber & $\mathrm{W}$ & In \\
\hline 110. & $\begin{array}{l}\text { H. validus (Miers) Bakh.f. ex } \\
\text { Forman }\end{array}$ & Menispermaceae & Agni foli & Woody climber & $\mathrm{W}$ & In. \\
\hline 111. & Helicia erratica Hook.f. & Proteaceae & Kharo pakan & Small tree & W & In \\
\hline 112. & Hibiscus sabdariffa $\mathrm{L}$. & Malvaceae & Lal mesta & Large herb & $\mathrm{C} \& \mathrm{~W}$ & Ex \\
\hline 113. & Hovenia dulcis Thumb. & Rhamnaceae & Raisil gaas & Medium tree & $\mathrm{W}$ & In \\
\hline 114. & $\begin{array}{l}\text { Hylocereus undatus (Howorth) } \\
\text { Britton \& Rose }\end{array}$ & Cactaceae & Dragon fruit & Spiny shrub & $\mathrm{C}$ & Ex \\
\hline 115. & Ixora pavetta Andr. & Rubiaceae & $\begin{array}{l}\text { Sweet rangan, } \\
\text { Gandha irangan }\end{array}$ & Bushy shrub & W & In \\
\hline 116. & Lantana trifolia $\mathrm{L}$. & Verbenaceae & Tinpata Lantana & Perennial herb & W & In \\
\hline 117. & Leea crispa $\mathrm{L}$. & Leeaceae & Kukura & Large shrub & W & In \\
\hline 118. & L. indica Merr. & Leeaceae & Kukur gibba & Large shrub & W & In \\
\hline 119. & $\begin{array}{l}\text { L. macrophylla Roxb. Ex } \\
\text { Hornem. }\end{array}$ & Leeaceae & Hostikorno & Large shrub & $\mathrm{W}$ & In \\
\hline 120. & $\begin{array}{l}\text { Lepisanthes rubiginosa (Roxb.) } \\
\text { Leenh. }\end{array}$ & Sapindaceae & Rubiharina & Small tree & $\mathrm{W}$ & In \\
\hline 121. & L. senegalensis (Poir.) Leenh. & Sapindaceae & $\begin{array}{l}\text { Gotaharina, } \\
\text { Amjam }\end{array}$ & Small tree & $\mathrm{W}$ & In \\
\hline 122. & Limonia acidissima $\mathrm{L}$. & Rutaceae & Koethbel & Medium tree & $\mathrm{C}$ & In \\
\hline 123. & Litsea cubeba (Lour.) Pers. & Lauraceae & Kubahoria & Large shrub & $\mathrm{W}$ & In \\
\hline 124. & L. glutinosa (Lour.) L.B. Rob. & Lauraceae & $\begin{array}{l}\text { Kukur chita, } \\
\text { Menda }\end{array}$ & Medium tree & W & In \\
\hline
\end{tabular}


Table 1 Contd.

\begin{tabular}{|c|c|c|c|c|c|c|}
\hline $\begin{array}{l}\text { Sl. } \\
\text { No. }\end{array}$ & Botanical Name & Family name & Local Names & Habit & $\begin{array}{l}\text { Cultivated } \\
\text { (C)/ } \\
\text { Wild (W) } \\
\end{array}$ & $\begin{array}{c}\text { Indigenous } \\
\text { (In)/ } \\
\text { Exotic (E) }\end{array}$ \\
\hline 125. & $\begin{array}{l}\text { Maclura cochinchinensis (Lour.) } \\
\text { Corner }\end{array}$ & Moraceae & China maclur & Large shrub & $\mathrm{W}$ & In \\
\hline 126. & $\begin{array}{l}\text { Madhuca longifolia (J. } \\
\text { Koenig ex L.) J.F.Machr. }\end{array}$ & Sapotaceae & $\begin{array}{l}\text { Mohua, Mohwa } \\
\text { maul }\end{array}$ & Medium tree & $\mathrm{W} \& \mathrm{C}$ & In \\
\hline 127. & $\begin{array}{l}\text { Maesa chisia Buch.-Ham. ex } \\
\text { D.Don }\end{array}$ & Myrsinaceae & $\begin{array}{l}\text { Bilouni, Gangu } \\
\text { loda }\end{array}$ & Large shrub & $\mathrm{W}$ & In \\
\hline 128. & M. ramentacea (Roxb.)A.DC. & Myrsinaceae & $\begin{array}{l}\text { Moricha, Noa } \\
\text { moricha }\end{array}$ & Small tree & W & In \\
\hline 129. & Malpighia coccigera $\mathrm{L}$. & Malpighiaceae & Kanta malpighia & Dwarf shrub & $\mathrm{C}$ & Ex \\
\hline 130. & M. glabra $\mathrm{L}$. & Malpighiaceae & - & Bushy shrub & $\mathrm{C}$ & Ex \\
\hline 131. & Mangifera sylvatica Roxb. & Anacardiaceae & Uriaam, Jangli & Large tree & W & In \\
\hline 132. & $\begin{array}{l}\text { Manilkara hexandra (Roxb.) } \\
\text { Dubard }\end{array}$ & Sapotaceae & $\begin{array}{l}\text { Khirni, Khir } \\
\text { khejur, Khiluni }\end{array}$ & Large tree & $\mathrm{W}$ & In \\
\hline 133. & M. zapota (L.) P.Royen & Sapotaceae & Sofeda, Sapodilla & Small tree & $\mathrm{C}$ & Ex \\
\hline 134. & Melastoma malabathricum $\mathrm{L}$. & Melastomataceae & $\begin{array}{l}\text { Ban-tejpata, } \\
\text { Datranga }\end{array}$ & Large shrub & W & Ex \\
\hline 135. & $\begin{array}{l}\text { Meliosma pinnata (Roxb.) } \\
\text { Walp. }\end{array}$ & Sabiaceae & Bativa, Adalia & Small tree & $\mathrm{W}$ & In \\
\hline 136. & Meyna spinosa Roxb. ex Link & Rubiaceae & Maina, Mainakata & Small tree & W & In \\
\hline 137. & Microcos paniculata $\mathrm{L}$. & Tiliaceae & $\begin{array}{l}\text { Asar, Tarah, } \\
\text { Pesondi, Pichunti }\end{array}$ & Small tree & W & In \\
\hline 138. & $\begin{array}{l}\text { Miliusa tomentosa (Roxb.) } \\
\text { J.Sinclair }\end{array}$ & Annonaceae & Lom tasbi & Erect shrub & W & In \\
\hline 139. & $\begin{array}{l}\text { M. velutina (Dunal) Hook.f. } \\
\text { \&. Thomson }\end{array}$ & Annonaceae & $\begin{array}{l}\text { Gandhi gajari, } \\
\text { Bul gajari }\end{array}$ & Small tree & $\mathrm{W}$ & In \\
\hline 140. & Mimusops elengi $\mathrm{L}$. & Sapotaceae & Bokul, Elengi & Medium tree & $\mathrm{C}$ & In \\
\hline 141. & $\begin{array}{l}\text { Mischocarpus pentapetalous } \\
\text { (Roxb.) Radlk. }\end{array}$ & Sapindaceae & Miskaphal & Medium tree & W & In \\
\hline 142. & Monstera deliciosa Liebm. & Araceae & Makhna & $\begin{array}{l}\text { Epiphytic } \\
\text { climber }\end{array}$ & $\mathrm{W}$ & In \\
\hline 143. & Morinda citrifilia $\mathrm{L}$. & Rubiaceae & Naniphal & Large shrub & $C \& W$ & In \\
\hline 144. & Morus alba $\mathrm{L}$. & Moraceae & Tunt, Tuti & Small tree & $\mathrm{C}$ & Ex \\
\hline 145. & M. indica $\mathrm{L}$. & Moraceae & Deshi tut & Large shrub & $\mathrm{C}$ & Ex \\
\hline 146. & M. macroura Miq. & Moraceae & Himalyan tut & Large shrub & $\mathrm{C}$ & Ex \\
\hline 147. & M. nigra $\mathrm{L}$. & Moraceae & Kalo tut & Large shrub & $\mathrm{C}$ & Ex \\
\hline 148. & Muntingia calabura $\mathrm{L}$. & Tiliaceae & Suji phal & Small tree & $\mathrm{C}$ & \\
\hline 149. & Murraya koenigii (L.) Spreng. & Rutaceae & Kari pata & Bushy shrub & $\mathrm{W} \& \mathrm{C}$ & In \\
\hline 150. & M. paniculata (L.) Jack & Rutaceae & Kamini, & Tall shrub & $\mathrm{C}$ & In \\
\hline 151. & $\begin{array}{l}\text { Myrciaria cauliflora (DC.) } \\
\text { Berg }\end{array}$ & Myrtaceae & Jaboticaba & Small tree & $\mathrm{C}$ & Ex \\
\hline 152. & Myrica nagi Thumb. & Myricaceae & Kayphol & Small tree & W & In \\
\hline 153. & Nauclea orientalis (L.) L. & Rubiaceae & Nukli & Erect shrub & W & In \\
\hline 154. & Nelumbo nucifera Gaertn. & Nelumbonaceae & Padma, Lotus & $\begin{array}{l}\text { Perennial } \\
\text { aquatic herb }\end{array}$ & $\mathrm{W} \& \mathrm{C}$ & In \\
\hline 155. & $\begin{array}{l}\text { Nephelium rambutan-ake } \\
\text { (Labill.) Leenh. }\end{array}$ & Sapindaceae & Rambutan & Medium tree & $\mathrm{C}$ & Ex \\
\hline
\end{tabular}


Table 1 Contd.

\begin{tabular}{|c|c|c|c|c|c|c|}
\hline $\begin{array}{l}\text { Sl. } \\
\text { No. }\end{array}$ & Botanical Name & Family name & Local Names & Habit & $\begin{array}{l}\text { Cultivated } \\
\text { (C)/ } \\
\text { Wild (W) }\end{array}$ & $\begin{array}{c}\text { Indigenous } \\
\text { (In)/ } \\
\text { Exotic (E) }\end{array}$ \\
\hline 156. & Nypa fruticans Wurmb. & Arecaceae & $\begin{array}{l}\text { Golpata, Gulga, } \\
\text { Gabna }\end{array}$ & Erect shrub & $\mathrm{W}$ & In \\
\hline 157. & $\begin{array}{l}\text { Nyssa javanica (Blume) } \\
\text { Wangerin }\end{array}$ & Nyssaceae & Malatilata & Tree & W & In \\
\hline 158. & Olax scandens Roxb. & Olacaceae & Koko aru & Climbing shrub & $\mathrm{W}$ & In \\
\hline 159. & Opuntia dellenii Haw. & Cactaceae & Phanimanasa & Under shrub & $\mathrm{C} \& \mathrm{~W}$ & Ex \\
\hline 160. & Ottelia alismoides (L.) Pers. & Hydrocharitaceae & Panicola & $\begin{array}{l}\text { Perennial } \\
\text { aquatic herb }\end{array}$ & W & In \\
\hline 161. & $\begin{array}{l}\text { Oxystelma secamone } \mathrm{H} . \\
\text { Karst. }\end{array}$ & Asclepiadaceae & $\begin{array}{l}\text { Dudhia lata, } \\
\text { Dudh lata }\end{array}$ & Woody climber & $\mathrm{W}$ & In \\
\hline 162. & Parkia roxburghii G.Don. & Mimosaceae & Kuki tetoi, Sapota & Small tree & $\mathrm{W}$ & In \\
\hline 163. & Passiflora edulis Sims. & Passifloraceae & $\begin{array}{l}\text { Tang, Passion } \\
\text { fruit, Granadilla }\end{array}$ & Tendril climber & $\mathrm{C}$ & Ex \\
\hline 164. & P. foetida $\mathrm{L}$. & Passifloraceae & Jhumka lata & Climbing herb & W & Ex \\
\hline 165. & P. quadrangularis $\mathrm{L}$. & Passifloraceae & Misriphal & Large climber & $\mathrm{C}$ & Ex \\
\hline 166. & Persea americana P. Mill. & Lauraceae & Avocado & Medium tree & $\mathrm{C}$ & Ex \\
\hline 167. & $\begin{array}{l}\text { Phoebe attenuata (Nees) } \\
\text { Nees }\end{array}$ & Lauraceae & Bonsum & Large tree & $\mathrm{C}$ & Ex \\
\hline 168. & Phoenix acaulis Roxb. & Arecaceae & Khudi khejur & Erect shrub & W & In \\
\hline 169. & P. dactylifera $\mathrm{L}$. & Arecaceae & Arabi khejur & Thorny tree & $\mathrm{C}$ & Ex \\
\hline 170. & P. paludosa Roxb. & Arecaceae & Hatal, Hintal & Erect shrub & W & In \\
\hline 171. & P. rupicola T.Anderson & Arecaceae & Kola khejur & Small tree & $\mathrm{C}$ & Ex \\
\hline 172. & P. sylvestris (L.) Roxb. & Arecaceae & Deshi khejur & Small tree & $C \& W$ & In \\
\hline 173. & Photinia arguta Wall.exLindl. & Rosaceae & Fotini & Small tree & $\mathrm{W}$ & In \\
\hline 174. & $\begin{array}{l}\text { Phyllanthus acidus (L.) } \\
\text { Skeels }\end{array}$ & Euphorbiaceae & Amla, Orbori & Small tree & C. & Ex \\
\hline 175. & P. emblica $\mathrm{L}$. & Euphorbiaceae & Amloki & Small tree & $\mathrm{W} \& \mathrm{C}$ & In \\
\hline 176. & P. urinaria $\mathrm{L}$. & Euphorbiaceae & Hazarmani & Annual herb & $\mathrm{W}$ & In \\
\hline 177. & Physalis minima $\mathrm{L}$. & Solanaceae & Fotka & Annual herb & $\mathrm{W}$ & In \\
\hline 178. & P. peruviana $\mathrm{L}$. & Solanaceae & Tepari & Annual herb & $\mathrm{C}$ & Ex \\
\hline 179. & $\begin{array}{l}\text { Pithecellobium dulce (Roxb.) } \\
\text { Benth. }\end{array}$ & Mimosaceae & $\begin{array}{l}\text { Khai babla, Jilapi } \\
\text { phul }\end{array}$ & Medium tree & $\mathrm{W} \& \mathrm{C}$ & Ex \\
\hline 180. & $\begin{array}{l}\text { Polyalthea cerasoides (Roxb.) } \\
\text { Benth. \& Hook.f. ex Bedd. }\end{array}$ & Annonaceae & Marmi & Small tree & $\mathrm{W}$ & In \\
\hline 181. & $\begin{array}{l}\text { Polyalthia suberosa } \\
\text { (Roxb.)Thwaites }\end{array}$ & Annonaceae & $\begin{array}{l}\text { Murmuri, } \\
\text { Kukuriam }\end{array}$ & Small tree & $\mathrm{W}$ & Ex \\
\hline 182. & $\begin{array}{l}\text { Pouteria campechiana } \\
\text { (Kunth) Baehni }\end{array}$ & Sapotaceae & Jaman phol & Small tree & $\mathrm{C}$ & Ex \\
\hline 183. & $\begin{array}{l}\text { Premna bengalensis } \\
\text { C.B.Clarke }\end{array}$ & Verbenaceae & $\begin{array}{l}\text { Banglalatana, } \\
\text { Koya jarul }\end{array}$ & Large shrub & $\mathrm{W}$ & In \\
\hline 184. & P. herbacea Roxb. & Verbenaceae & $\begin{array}{l}\text { Bhuijam, Mati } \\
\text { jam }\end{array}$ & Undershrub & $\mathrm{W}$ & In \\
\hline 185. & $\begin{array}{l}\text { Protium serratum (Wall. ex } \\
\text { Coelbr.) Engl. }\end{array}$ & Burseraceae & $\begin{array}{l}\text { Chitrica, } \\
\text { Gutgutya, Hajna }\end{array}$ & Medium tree & W & In \\
\hline 186. & Psidium araca Raddi & Myrtaceae & Tock piyara & Large shrub & $\mathrm{W}$ & Ex / In \\
\hline 187. & P. chinense Lodd. ex Loud. & Myrtaceae & Chinese piyara & Large shrub & $\mathrm{C}$ & Ex \\
\hline
\end{tabular}


Table 1 Contd.

\begin{tabular}{|c|c|c|c|c|c|c|}
\hline $\begin{array}{l}\text { Sl. } \\
\text { No. }\end{array}$ & Botanical Name & Family name & Local Names & Habit & $\begin{array}{l}\text { Cultivated } \\
\text { (C)/ } \\
\text { Wild (W) }\end{array}$ & $\begin{array}{c}\text { Indigenous } \\
\text { (In)/ } \\
\text { Exotic (E) }\end{array}$ \\
\hline 188. & Pterygota alata (Roxb.) R.Br. & Sterculiaceae & Buddha narical & Large tree & $\mathrm{W} \& \mathrm{C}$ & In \\
\hline 189. & Punica granatum $\mathrm{L}$. & Punicaceae & Dalim, Bedana, & Large shrub & $\mathrm{C}$ & Ex \\
\hline 190. & Randia angustissima Wall. & Rubiaceae & $\begin{array}{l}\text { Belong, Moncata, } \\
\text { Piralo }\end{array}$ & $\begin{array}{l}\text { Tree or large } \\
\text { shrub }\end{array}$ & W & In \\
\hline 191. & R. dumatorium (Retz.) Lam. & Rubiaceae & $\begin{array}{l}\text { Moncata, } \\
\text { Mainphal }\end{array}$ & Small tree & $\mathrm{W}$ & In \\
\hline 192. & $\begin{array}{l}\text { Rhaphidophora pertusa } \\
\text { (Roxb.) Schott }\end{array}$ & Araceae & Tusafido & $\begin{array}{l}\text { Epiphytic } \\
\text { climber }\end{array}$ & $\mathrm{W}$ & In \\
\hline 193. & Rhizophora mucronata Lam. & Rhizophoraceae & Khamo & Small tree & $\mathrm{W}$ & In \\
\hline 194. & Salacia chinensis L. & Hippocrateaceae & $\begin{array}{l}\text { Madhu phal, } \\
\text { Chota boroi }\end{array}$ & $\begin{array}{l}\text { Woody } \\
\text { climber }\end{array}$ & W & In \\
\hline 195. & $\begin{array}{l}\text { S. salacioides (Roxb.) Rolla } \\
\text { Rao \& Hemadri }\end{array}$ & Hippocrateaceae & Sala madhu phal & $\begin{array}{l}\text { Woody } \\
\text { climber }\end{array}$ & $\mathrm{W}$ & In \\
\hline 196. & Sambucus canadensis $\mathrm{L}$. & Caprifoliaceae & American elder & Erect shrub & W & Ex \\
\hline 197. & S. javanica Reinw. ex Blume & Caprifoliaceae & Hoklati & Small tree & W & Ex \\
\hline 198. & S. nigra L. & Caprifoliaceae & Sambucas & Small tree & $\mathrm{C}$ & Ex \\
\hline 199. & Sandoricum indicum Cav. & Meliaceae & Santol & Medium tree & $\mathrm{C}$ & Ex \\
\hline 200. & Sarcolobus globosus Wall. & Asclepiadaceae & $\begin{array}{l}\text { Baoli-lata, Baoli- } \\
\text { phal }\end{array}$ & Large shrub & $\mathrm{W}$ & In \\
\hline 201. & Saurauia roxburghii Wall. & Theaceae & Dalup & Large shrub & $\mathrm{W}$ & In \\
\hline 202. & $\begin{array}{l}\text { Sauropus androgynus (L.) } \\
\text { Merr. }\end{array}$ & Euphorbiaceae & Mithapotro & Large shrub & $\mathrm{W}$ & In \\
\hline 203. & $\begin{array}{l}\text { Schleichera oleasa (Lour.) } \\
\text { Merr. }\end{array}$ & Sapindaceae & Kusum, Joyna & Medium tree & $\mathrm{C}$ & In \\
\hline 204. & Semecarpus anacardium L.f. & Anacardiaceae & Bhela, Beda & Medium tree & W & In \\
\hline 205. & S. nigroviridis Thwaites & Anacardiaceae & Kattula & Medium tree & $\mathrm{E}$ & In \\
\hline 206. & Shorea robusta Gaertn.f. & Dipterocarpaceae & Shal, Gazari & Medium tree & $\mathrm{W} \& \mathrm{C}$ & In \\
\hline 207. & Solanum americanum Mill. & Solanaceae & Tit begun & Annual herb & W & In \\
\hline 208. & S. lasiocarpum Dunal & Solanaceae & Kantha sola & $\begin{array}{l}\text { Herb or } \\
\text { Undershrub }\end{array}$ & $\mathrm{W}$ & In \\
\hline 209. & S. trilobatum $\mathrm{L}$. & Solanaceae & Trikun pata & $\begin{array}{l}\text { Herb or } \\
\text { Undershrub }\end{array}$ & $\mathrm{W}$ & In \\
\hline 210. & $\begin{array}{l}\text { Solena amplexicaulis (Lam.) } \\
\text { Gandhi }\end{array}$ & Cucurbitaceae & $\begin{array}{l}\text { Kundri, Rakhal } \\
\text { gota }\end{array}$ & Climbing herb & $\mathrm{W}$ & In \\
\hline 211. & $\begin{array}{l}\text { Sonneratia caseolaris (L.) } \\
\text { Engl. }\end{array}$ & Sonneratiaceae & $\begin{array}{l}\text { Ora, Orali, Orcha, } \\
\text { Shoila }\end{array}$ & Large tree & W & In \\
\hline 212. & Spodius dulcis Parkinson & Anacardiaceae & Bilati amra & Small tree & $\mathrm{C}$ & Ex \\
\hline 213. & S. purpurea $\mathrm{L}$. & Anacardiaceae & Beelati amra & Medium tree & $\mathrm{C}$ & Ex \\
\hline 214. & Sterculia foetida $\mathrm{L}$. & Sterculiaceae & Jangli-the & Medium tree & W & In \\
\hline 215. & $\begin{array}{l}\text { Stixis suaveolens (Roxb.) } \\
\text { Pierre }\end{array}$ & Capparaceae & Madhumalati & $\begin{array}{l}\text { Woody } \\
\text { climber }\end{array}$ & $\mathrm{W}$ & In \\
\hline 216. & $\begin{array}{l}\text { Suregada multiflora (A. } \\
\text { Juss.) Baill }\end{array}$ & Euphorbiaceae & Ban naranga & Medium tree & $\mathrm{W}$ & In \\
\hline 217. & $\begin{array}{l}\text { Syzygium aqueum (Burm.f.) } \\
\text { Alston }\end{array}$ & Myrtaceae & Jamboo, Pani jam & Medium tree & $\mathrm{W}$ & In \\
\hline 218. & $\begin{array}{l}\text { S. balsameum (Wight) } \\
\text { Wall. ex Walp. }\end{array}$ & Myrtaceae & Buti jam & Large Shrub & $\mathrm{W}$ & In \\
\hline
\end{tabular}


Table 1 Contd.

\begin{tabular}{|c|c|c|c|c|c|c|}
\hline $\begin{array}{l}\text { Sl. } \\
\text { No. }\end{array}$ & Botanical Name & Family name & Local Names & Habit & $\begin{array}{c}\text { Cultivated } \\
\text { (C)/ } \\
\text { Wild (W) }\end{array}$ & $\begin{array}{c}\text { Indigenous } \\
\text { (In)/ } \\
\text { Exotic (E) }\end{array}$ \\
\hline 219. & $\begin{array}{l}\text { S. claviflorum (Roxb.) Wall. } \\
\text { ex A.M.Cowan \& Cowan }\end{array}$ & Myrtaceae & Lamba nali jam, & Small tree & $\mathrm{W}$ & In \\
\hline 220. & S. cymosum (Lam.) DC. & Myrtaceae & $\begin{array}{l}\text { Khudi jam, } \\
\text { Khurijam }\end{array}$ & Small tree & $\mathrm{W}$ & In \\
\hline 221. & S. formosum (Wall.) Masam. & Myrtaceae & $\begin{array}{l}\text { Paniya jam, } \\
\text { Phuljam, Natla }\end{array}$ & Medium tree & W & In \\
\hline 222. & S. fruticosum (Roxb.) DC. & Myrtaceae & $\begin{array}{l}\text { Ban jam, Kak jam, } \\
\text { Puti jam }\end{array}$ & Small tree & W & In \\
\hline 223. & S. jambos (L.) Alston & Myrtaceae & Gulap jam & Small tree & $\mathrm{C}$ & Ex \\
\hline 224. & S. macrocarpa Roxb. & Myrtaceae & $\begin{array}{l}\text { Chalita jam, Bon } \\
\text { jam }\end{array}$ & Medium tree & $\mathrm{W}$ & In \\
\hline 225 & S. malaccense (L.) Merr. \& Perry. & Myrtaceae & Jamrul & Medium tree & $\mathrm{C}$ & Ex \\
\hline 226. & $\begin{array}{l}\text { S. nervosum (DC.) } \\
\text { A. Cunnex DC. }\end{array}$ & Myrtaceae & $\begin{array}{l}\text { Boti jam, Dapha } \\
\text { jam, Goda jam }\end{array}$ & Small tree & $\mathrm{W} \& \mathrm{C}$ & In \\
\hline 227. & $\begin{array}{l}\text { S. oblatum (Roxb.) } \\
\text { A.M. Cowan \& Cowan }\end{array}$ & Myrtaceae & Gola jam & Medium tree & $\mathrm{W}$ & In \\
\hline 228. & $\begin{array}{l}\text { S. praecox (Roxb.) } \\
\text { Rathakr \& N.C.Nair }\end{array}$ & Myrtaceae & Poora jam & Medium tree & $\mathrm{W}$ & In \\
\hline 229. & $\begin{array}{l}\text { S. samarangense (Blume) } \\
\text { Merr. \& L.M.Perry }\end{array}$ & Myrtaceae & -- & Medium tree & $\mathrm{C}$ & Ex \\
\hline 230. & $\begin{array}{l}\text { S. tetragonum (Wight) } \\
\text { Wall. ex. Kurz }\end{array}$ & Myrtaceae & Gonojam, Charjam & Medium tree & $\mathrm{W}$ & In \\
\hline 231. & Tamarindus indica $\mathrm{L}$. & Caesalpiniaceae & Tentul, Tentuli & Large tree & $\mathrm{C} \& \mathrm{~W}$ & Ex \\
\hline 232. & Tapiria hirsuta Hook.f. & Anacardiaceae & Lomam & Scandent shrub & $\mathrm{W}$ & In \\
\hline 233. & $\begin{array}{l}\text { Termilania bellirica (Gaertn.) } \\
\text { Roxb. }\end{array}$ & Combretaceae & Bohera, Boyra & Medium tree & $\mathrm{W} \& \mathrm{C}$ & In \\
\hline 234. & T. catappa $\mathrm{L}$. & Combretaceae & Kathbadam & Small tree & $\mathrm{C} \& \mathrm{~W}$ & Ex \\
\hline 235. & T. chebula (Gaertn.) Retz. & Combretaceae & Haritoki & Medium tree & $\mathrm{W} \& \mathrm{C}$ & In \\
\hline 236. & $\begin{array}{l}\text { T. citrina (Gaertn.) } \\
\text { Roxb. ex Fleming }\end{array}$ & Combretaceae & $\begin{array}{l}\text { Hatiyal, Haritaki, } \\
\text { Harra }\end{array}$ & Medium tree & W & In \\
\hline 237. & $\begin{array}{l}\text { Tetrastigma angustifolim } \\
\text { (Roxb.) Planch. }\end{array}$ & Vitaceae & $\begin{array}{l}\text { Nekung riubi, } \\
\text { Sarupatilata }\end{array}$ & $\begin{array}{l}\text { Herbaceous } \\
\text { climber }\end{array}$ & $\mathrm{W}$ & In \\
\hline 238. & T. bracteolatum (Wall.) Planch. & Vitaceae & Golgoli lata & $\begin{array}{l}\text { Herbaceous } \\
\text { climber }\end{array}$ & $\mathrm{W}$ & In \\
\hline 239. & T. dubium (Lawson) Planch. & Vitaceae & Kuannia, Riam lata & Climbing herb & W & \\
\hline 240 & $\begin{array}{l}\text { T. leucostaphyllum (Den.) } \\
\text { Alston. }\end{array}$ & Vitaceae & Horina lata & Climbing herb & W & In \\
\hline 241. & T. serrulatum (Roxb.) Planch. & Vitaceae & Koratilata & Climbing shrub & $\mathrm{W}$ & In \\
\hline 242. & Trapa bispinosa Roxb. & Trapaceae & Paniphal & $\begin{array}{l}\text { Floating aquatic } \\
\text { herb }\end{array}$ & $\mathrm{W} \& \mathrm{C}$ & In \\
\hline 243. & T. maximowiczii Korshinsky & Trapaceae & $\begin{array}{l}\text { Paniphal, } \\
\text { Kata singhara }\end{array}$ & $\begin{array}{l}\text { Floating aquatic } \\
\text { herb }\end{array}$ & W & In \\
\hline 244. & $\begin{array}{l}\text { Triphasia trifolia (Burm.f.) P. } \\
\text { Wilson }\end{array}$ & Rutaceae & Cheeninarangi & Small tree & $\mathrm{W}$ & In \\
\hline 245 & Uvaria ferruginea Buch.-Ham. & Annonaceae & Bon khajur & Large shrub & W & In. \\
\hline 246. & Vitex glabrata R.Br. & Verbenaceae & Ashal & Medium tree & $\mathrm{W}$ & In \\
\hline 247. & Vitis lanata Roxb. & Vitaceae & $\begin{array}{l}\text { Sonalata, } \\
\text { Rangobhuttu }\end{array}$ & Climbing shrub & $\mathrm{W}$ & In \\
\hline
\end{tabular}


Table 1 Contd.

\begin{tabular}{|c|c|c|c|c|c|c|}
\hline $\begin{array}{l}\text { Sl. } \\
\text { No. }\end{array}$ & Botanical Name & Family name & Local Names & Habit & $\begin{array}{c}\text { Cultivated } \\
\text { (C)/ } \\
\text { Wild (W) }\end{array}$ & $\begin{array}{l}\text { Indigenous } \\
\text { (In)/ } \\
\text { Exotic (E) }\end{array}$ \\
\hline 248. & Willoughbeia edulis Roxb. & Apocynaceae & Lata aam, Lati aam & Climbing shrub & $\mathrm{W}$ & In \\
\hline 249. & $\begin{array}{l}\text { Xerospermum laevigatum } \\
\text { Radlk. }\end{array}$ & Sapindaceae & Bonlichu & Small tree & W & In \\
\hline 250. & $\begin{array}{l}\text { X. noronhianum (Blume) } \\
\text { Blume }\end{array}$ & Sapindaceae & $\begin{array}{l}\text { Bonlichu, } \\
\text { Noronlichu }\end{array}$ & $\begin{array}{l}\text { Medium } \\
\text { tree }\end{array}$ & $\mathrm{W}$ & In \\
\hline 251. & $\begin{array}{l}\text { Ziziphus funiculosa Buch.- } \\
\text { Ham. ex Wall. }\end{array}$ & Rhamnaceae & Bon-boguri & Large shrub & W & In \\
\hline 252. & Z. galabrata Heyne ex Roth & Rhamnaceae & $\begin{array}{l}\text { Rata boroi, Jangli } \\
\text { kul }\end{array}$ & Small tree & W & In \\
\hline 253. & Z. oenoplia (L.) Mill. & Rhamnaceae & $\begin{array}{l}\text { Sial kul, Jangal kul, } \\
\text { Bon boroi }\end{array}$ & Straggling shrub & W & In \\
\hline 254. & Z. rugosa Lam. & Rhamnaceae & $\begin{array}{l}\text { Jangli boroi, } \\
\text { Rug boroi }\end{array}$ & $\begin{array}{l}\text { Straggling shrub } \\
\text { or small tree }\end{array}$ & W & In \\
\hline 255. & Z. xylopyrus (Retz.) Willd. & Rhamnaceae & Jhangli boroi & Large shrub & W & In \\
\hline
\end{tabular}

Table 2. Some promising wild minor fruit yielding plant species of Bangladesh.

\begin{tabular}{|c|c|c|c|c|c|}
\hline & Name of the species & Edible part & & Name of the species & Edible part \\
\hline 1 & Alangium savifolium & Pulp & 23 & Hovenia dulcis & Pulp \\
\hline 2 & Antidesma acidum & Fruit & 24 & Morinda citrifolia & Thalamus \\
\hline 3 & A. ghaesembilla & Pulp & 25 & Morus macroura & Ripe fruit \\
\hline 4 & Arocarpus chama & Pulp & 26 & Murrya koenigii & Pulp \\
\hline 5 & Bauea barmanica & Pulp & 27 & Paramigyna citrifolia & Pulp \\
\hline 6 & Bauhinia vahlii & Immature seed & 28 & Parkia roxburghii & Pulp \\
\hline 7 & Buchanania lanzan & Fruit \& Nut & 29 & Passiflora foetida & Ripe fruit \\
\hline 8 & Caesalpinia digyna & Immature seed & 30 & Phoebe attenuta & Pulp \\
\hline 9 & Carissa spinarum & Pulp & 31 & Photina arguta & Ripe fruit \\
\hline 10 & Castanopsis indica & Matured seed & 32 & Physalis minima & Ripe fruit \\
\hline 11 & C. purpurella & Matured seed & 33 & Randia dumetorium & Matured fruit \\
\hline 12 & Cirus assamensis & Juice & 34 & R. spinosa & Matured fruit \\
\hline 13 & Cleistocalyx operculata & Seed kernel & 35 & R. uliginosa & Matured fruit \\
\hline 14 & Cordia dichotoma & Pulp & 36 & Salacia salacioides & Matured fruit \\
\hline 15 & Diospyros peregrina & Pulp & 37 & Sambucus canadensis & Matured fruit \\
\hline 16 & Duchesnia indica & Matured thalamus & 38 & S. javanica & Matured fruit \\
\hline 17 & Erioglossum rubignossum & Pulp & 39 & S. nigra & Matured fruit \\
\hline 18 & Eryobotrya javanica & Pulp & 40 & Schleichera oleosa & Arillous pulp \\
\hline 19 & Euryale ferox & Immature seed & 41 & Sterculea foetida & Kernel \\
\hline 20 & Firmiana colorata & Matured seed & 42 & Sysyzium formosum & Pulp \\
\hline 21 & Garcinia xanthochymus & Pulp & 43 & S. аquеит & Pulp \\
\hline 22 & Haematocarpus validus & Pulp & 44 & Willoubeia edulis & Pulp \\
\hline
\end{tabular}


Among the species recorded, a total of 50 species are herbs, including 31 species of climbers or lianas, and 49 species are shrubby in nature. The remaining 156 species are trees. About 48 species are cultivated for fruits and the 35 species are both cultivated and wild. The remaining species are exclusively wild. A total of 53 exotic species are included in the cultivation state. Only 3 species are found growing in aquatic condition.

Almost all the species produce true fruits and only five species produce false fruits. Few species are considered as nut or kernel producing tree. Only 15 species produce fruits that are completely edible and 13 species produce such fruits only the kernel or nut of which are edible. In other cases, all the structural portions except the seed(s) are edible.

Almost all the exotic species are cultivated and considered as promising fruit yielding plants. Some native wild and minor cultivated plants are also found promising fruit yielding in their taste and colour also. In this study, 44 species have been recognized as promising minor fruit yielding species because they are comparatively widely used and popular in consumption (Table 2).

The flowering and fruiting time of the edible fruit yielding plant species was found as remarkably variable (Table 1). The fruits were more or less available throughout the year (Fig. 3). The majority of minor fruit yielding plants were found with fruiting in the months between March and September. The richest fruit yielding month was June (11.51\%) and the poorest was January $(5.50 \%)$.

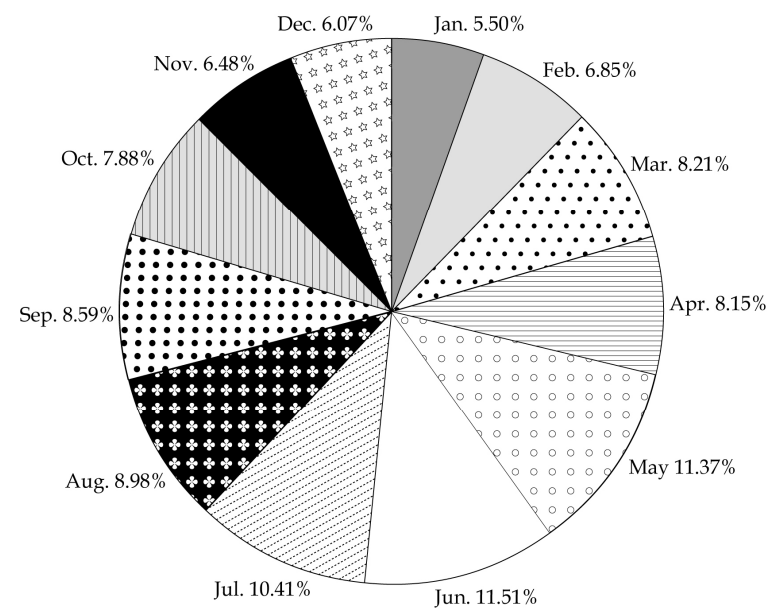

Fig. 3. Availability percentage of the edible minor fruits per month in a year in Bangladesh.

The edible fruits occur in a vast number of families in the World. Hill (1951) recognized the families Anacardiaceae, Annonaceae, Myrtaceae, Rutaceae, Sapotaceae and Sapindaceae as particularly important in yielding the fruits. This study has also found some similar important families.

In few reports some minor fruits are evaluated as promising in many aspects (Bose, 1985; Rahim et al., 2011; Frncesca et al., 2012). Many of the minor edible fruits are with little pulp and larger seed size with less palatable. However, the edibility and nutritional value and economic value of different minor edible fruits can be improved. On the other hand, most of the major fruits are available in the month of May to July, but minor fruits are available throughout the year. The minor fruits can play a great role in improving the social and economic status of the local people. They also can significantly contribute in the conservation of biodiversity. Minor fruit production 
may support the livelihood of the producers and side by side can increase the demand of the consumers. Many edible minor fruits can contribute as the remarkably promising fruit recourses in multifarious way if proper research is conducted for their exploration, selection, improvement and large-scale cultivation.

\section{References}

Ahmed, Z.U., Hassan M.A., Begum, Z.N.T., Khondker, M., Kabir, S.M.H., Ahmad, M., Ahmed, A.T.A., Rahman, A.K.A. and Haque, E.U. (Eds.). 2008-2009. Encyclopedia of Flora and Fauna of Bangladesh. Vols. 6, 7, 8, 9, 10 \& 12. Angiosperms (Dicotyledons); Vol. 12 Angiosperms (Monocotyledons). Asiatic Society of Bangladesh, Dhaka, pp. 1- 408, 546, 478; 488, 580, 399, 552 (respectively).

APCAEM. 2007. Enhancing export competitive of Asian fruits. UN-ESCAP, Beijing, China. https://www.researchgate.net/publication/270884737.

BBS. 2011. Statistical Yearbook of Bangladesh. Bangladesh Bureau of Statistics, Ministry of Planning, Govt. of Bangladesh, Dhaka, pp. 1-552

Begum, M. 2004. Edible Fruits of Bangladesh. In: Khan, M.S. (Ed). $2^{\text {nd }}$ Ed., Asiatic Civil Military Press, Dhaka, pp. 1-124.

Bose, T.K. 1985. Fruits of India, Tropical and Subtropical. Naya Prokash, Calcutta, pp 705.

Cronquist, A. 1988. The Evolution and Classification of Flowering Plants. Columbia Univ. Press, New York, pp. $1-535$

Das, D.K. 1982. Edible Fruits of Bangladesh Forests. Bull. 3; Plant Taxonomy Series, Forest Research Institute, Chittagong.

Francesca, G, Sara T, José, A, José, Q, Bruno M, and Maurizio B. 2012. The strawberry: Composition, nutritional quality, and impact on human health. Nutrition (Burbank, Los Angeles County, Calif.). 28. 919. 10.1016/j.nut.2011.08.009.

Grierson, A.J.C. and Long, D.G. 1983-1991. Flora of Bhutan (Including a Record of Plants from Sikkim). Vol.-1 (1, 2, 3) and 2 (1), Royal Botanic Garden, Edinburgh. U.K, pp. 1-186, 276, 372.

Guha-Bakshi, D.N. 1984. Flora of Murshidabad District, West Bengal, India. Scientific Pub., Jodhpur, India, pp. 1- 440

Heinig, R.L. 1925. List of Plants of the Chittagong Collectorate and the Hill Tracts. The Bengal Govt. Branch Press, Darjeeling, pp. 1-84.

Hill, A.F. 1951.Economic Botany. (2 ${ }^{\text {nd }}$. ed.) McGraw Hill Book Company, 1-New York, pp. 1-560.

Humphrey, G., Carter, A. and Dorine, N. 1921. Useful plants of the district of Lakhimpur, in Assam. Rec. Bot. Surv. India, 6: 353-420.

Joshi, B.D. 1998. Indigenous horticultural fruits of the Indian Himalayas. In: ManagingAgrodiversity (eds. Partap, T.and Sthapit, B.), International Centre for Integrated Mountain Development, Kathmandu, Nepal, pp. 205-221.

Khan, M.S. 1974. Flowers and Fruits of Bangladesh. Department of Publications. Ministry of Information \& Broadcasting, Govt. of Bangladesh, Dhaka, pp. 1-75.

Naskar, K. 1993. Plant Wealth of the Lower Gangetic Delta. Vol. 1 \& 2. Daya Pub. House, Delhi, pp. 1-820.

Noltie, H.J. 1994. Flora of Bhutan (Including a Record of Plants from Sikkim) Vol. 3, Royal Botanic Garden, Edinburgh, UK, pp. 1-641.

Pasha, M.K. and Uddin, S.B. 2013. Dictionary of Plant Names of Bangladesh (Vascular Plants). Janakalyan Prashani, Andarkilla, Chittagong, Bangladesh, pp. 1-434.

Rahim, M.A., Alam, A.K.M.A., Alam, M.S. and Anwar, M.M. (Eds.). 2011. Underutilized Fruits in Bangladeash. Bangladesh Agriculture University, Mymenshing, pp.205.

Rahman, M. and Rahman, J. 2014. Medicinal value and nutrient status of indigenous fruits of Bangladesh. Nova J. Medical Biol. Sci., 26: 1-19.

Rashid, M.M., Kadir, M.A. and Hossain, M.M. 1987. Bangladesher Phol (in Bangla). Rashid Publishing House, Joydevpur, Gazipur, pp. 1-430. 
Roy, M. 2007. Bangladesher Phol. (in Bangla). Dibyaprakash, Dhaka, pp. 1-315.

Siddiqui, K.U., Islam, M.A., Ahmed, Z.U., Begum, Z.N.T., Hassan, M.A., Khondker, M., Rahman M.M., Kabir, S.M.H., Ahmad, M., Ahmed, A.T.A., Rahman, A.K.A. and Haque, E.U. (eds.) 2007. Encyclopedia of Flora and Fauna of Bangladesh. Vol.11, Angiosperms (Monocotyledons). Asiatic Society of Bangladesh, Dhaka, pp. 1-399.

Srivastava, A.; Bishnoi, S. K. and Sarkar, P. K. (2017). Value Addition in Minor Fruits of Eastern India: An Opportunity to Generate Rural Employment. In: Dutta, A. K. and Mondal, B. (Eds.), Fruits for Livelihood: Production Technology and Management Practices. Agrobios (India), Jodhpur, India, pp. 395-417.

Suresh, C.P., Bhatia, K.D., Sukla, G., Pradhan, K. and Chakravarty, S. 2014. Wild edible tree fruits of Sikkim Himalayas. J. Tree Sci., 33(1): 12-33.

The Plant List 2010. Version 1. Published on the Internet; http://www.theplantlist.org/

Wilson, E.O. 1992. The Dictionary of Life. Penguin, London, pp. 1-440.

Zakri, A.H. and Mohammad, O. 1997. Genetic enhancement in new crops. In: Domestication, Production and Utilization of New Crops. (eds. Smartt, J. and Huq, N.). International Centre for Underutilized Crops. University of Southampton, U.K, pp.101-106.

(Manuscript received on 2 April, 2019 revised on 10 December, 2019) 